\title{
A MULTI-TRANSITION AND MULTI-ISOTOPE STUDY OF CO IN THE GIANT MOLECULAR CLOUD ORION-A
}

\author{
A. DUTREY, A. CASTETS, G. DUVERT \\ Groupe d'Astrophysique de Grenoble, \\ B.P.53X 38041 Grenoble, France.

\section{J. BALLY, W.D. LANGER, R.W. WILSON \\ ATET Bell laboratories, Box 400 Holmdel, New Jersey 07, USA.}

In order to study the excitation conditions in the Orion-A region, we applied an LVG code to ${ }^{12} \mathrm{CO},{ }^{13} \mathrm{CO}$ and $\mathrm{C}^{18} \mathrm{O}$ data obtained with the AT\&T Bell Laboratories 7-meter telescope in USA (CO isotopes: $J=1-0, \mathrm{CS}: J=2-1$ ) and the radiotelescope of the "Groupe d'Astrophysique de Grenoble" in France (CO isotopes : $J=2-1$ ).

Figure 1 presents the CS (2-1) integrated area map superimposed to the $\mathrm{C}^{18} \mathrm{O}$ (2-1) integrated area. Figure 2 corresponds to the $\mathrm{N}\left({ }^{13} \mathrm{CO}\right)$ map of the main filament ( referred as the $\int$ shape filament ) derived from our ${ }^{13} \mathrm{CO} L V G$ analysis (Castets et al. 1990 ). They show that contrarily to $\mathrm{C}^{18} \mathrm{O},{ }^{13} \mathrm{CO}$ do not probe the dense cores. However, some high $\mathrm{H}_{2}$ density, low column density features are revealed, not seen in $\mathrm{CS}$ and located in the envelope. Conversely the $\mathrm{C}^{18} \mathrm{O}$ map reveals that the same dense cores are seen in $\mathrm{CS}$ and $\mathrm{C}^{18} \mathrm{O}$ map suggesting in the Orion-A region a high density in the cores.

In the south (below $D e c=+2.5^{\prime}$, see the location in the maps) the ${ }^{13} \mathrm{CO}$ reveals several components with different excitation temperature and line opacities. The $\mathrm{C}^{18} \mathrm{O}$ analysis is consistent with the existence of four components $(V=7,8.3,9.1,10.1 \mathrm{~km} / \mathrm{s})$, especially below $D e c=-10^{\prime}$. Due to the opacity of ${ }^{13} \mathrm{CO}$ lines, they are not always clearly separated in the ${ }^{13} \mathrm{CO}$ data. Below $D e c=-10^{\prime}$, the ${ }^{13} \mathrm{CO}$ LVG analysis of the "main component" gives an average density of $1200 \mathrm{~cm}^{-3}$ and $\mathrm{N}\left({ }^{13} \mathrm{CO}\right)$ of $2 \cdot 10^{16} \mathrm{~cm}^{-2}$ while preliminary $\mathrm{C}^{18} \mathrm{O}$ results show an average $\mathrm{n}\left(\mathrm{H}_{2}\right)$ of $5000 \mathrm{~cm}^{-3}$ and $\mathrm{N}\left(\mathrm{C}^{18} \mathrm{O}\right)$ of $8 \cdot 10^{14} \mathrm{~cm}^{-2}$ for the brightest components.

The $\mathrm{n}\left(H_{2}\right)$ density obtained from $\mathrm{C}^{18} \mathrm{O}$ represents an average value along the line-of-sight, while the density derived from ${ }^{13} \mathrm{CO}$ probes only external layers. To get the density and to determine the excitation conditions in the cores, a CS study is on progress.

\section{Reference}

Castets A., Duvert G., Dutrey A., Bally J., Langer W.D., Wilson R.W Astron. Astrophys. 1990, in Press. 

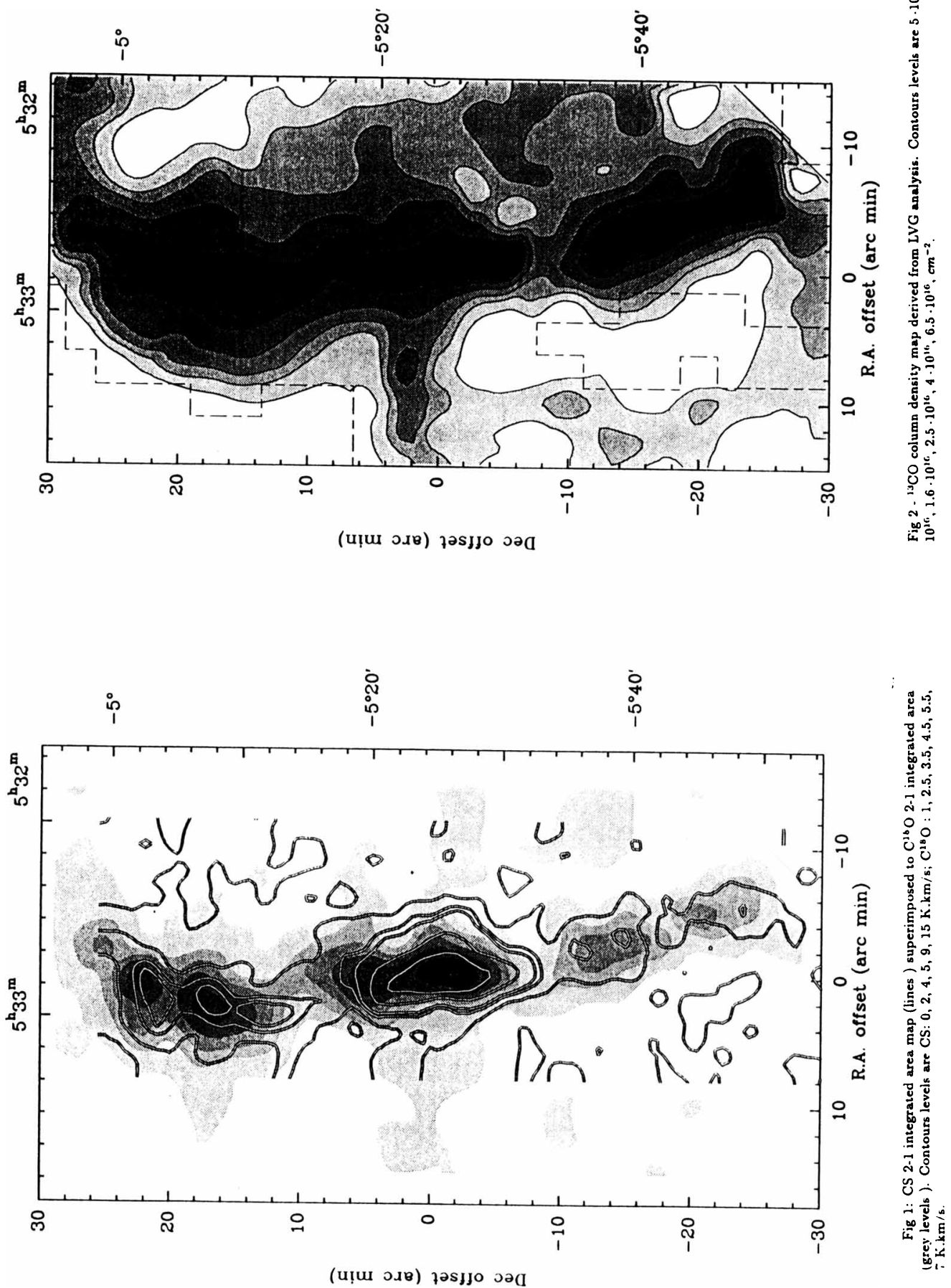